\title{
PERSISTENCE OF REAL EXCHANGE RATES IN THE CENTRAL AND EASTERN EUROPEAN COUNTRIES
}

\author{
Ahmad Zubaidi BAHARUMSHAH ${ }^{1}$, Siew-Voon SOON ${ }^{2}$, \\ Stilianos FOUNTAS ${ }^{3}$, Nurul Sima MOHAMAD SHARIFF ${ }^{4}$ \\ 1,2 Department of Economics, Faculty of Economics and Management, \\ Universiti Putra Malaysia, 43400 UPM Serdang Selangor, Malaysia \\ ${ }^{3}$ Department of Economics, University of Macedonia, 156 Egnatia Street, \\ GR-540 06 Thessaloniki, Greece \\ ${ }^{4}$ Faculty of Science and Technology,Universiti Sains Islam Malaysia, \\ Bandar Baru Nilai 71800 Nilai, Malaysia \\ E-mails: ${ }^{1}$ baharumshah@yahoo.com (corresponding author); \\ ${ }^{2}$ sv_soon2001@yahoo.com; ${ }^{3}$ sfountas@uom.gr; ${ }^{4}$ nurulsima@usim.edu.my \\ Received 15 September 2014; accepted 25 September 2014
}

\begin{abstract}
We investigate the mean reversion in real exchange rates for Central and Eastern European countries. We use point and confidence interval estimates from the Phillips et al.'s (2001) local-persistent model as our preferred measures of the persistence of real exchange rates. We find that the adjustment to purchasing power parity is more rapid after accounting for structural breaks, with half-life deviation from parity below 18 months, which is consistent with the explanation based on nominal rigidities. The estimated narrow confidence intervals for the half-lives invalidate the purchasing power parity puzzle for transition and some core European Union countries. The novelty of our results lies in the finding of strong evidence for purchasing power parity as the local-persistent model produces shorter half-lives and much narrower corresponding confidence intervals than those obtained by standard Dickey-Fuller and local-to-unity models. Our evidence for PPP suggests that the transition countries have maintained their long-run competitiveness against their trading partners.
\end{abstract}

Keywords: half-lives, local persistence, structural breaks, real exchange rate, PPP puzzle, transition economies.

JEL Classification: C22; E30; F31.

\section{Introduction}

The validity of purchasing power parity (PPP) as a long-run equilibrium relationship postulating that real exchange rates (RERs) are mean reverting is a hotly debated issue in the field of international macroeconomics as PPP represents a major building block of many open-economy macroeconomic models. Most previous studies, that include panel, linear, and nonlinear unit-root tests on RERs, have attempted to provide supporting evidence with mixed results. Lengthy half-lives for RERs in the presence of a high degree 
of exchange rate volatility have been considered as one of the most puzzling empirical regularities in international economics, the so-called PPP puzzle (Rogoff 1996). One common explanation for the puzzle is based on the low power of conventional unit-root tests, which is aggravated by the high persistence of RERs. The difficulty of rejecting the unit-root null is often associated with the shortness of samples used in the empirical analysis. The issue is more apparent in the transition countries, which are the main focus of this study, where a long span of data is unavailable. In addition, macroeconomic instability in the last three decades may have had a significant influence on the behavior of RERs making PPP testing a challenging task.

The PPP concept is of paramount importance for academic economists, policymakers and international investors. PPP allows for the determination of the degree of exchange rate misalignment. It also makes possible the comparison of national income levels across countries. PPP deviations are considered an important leading indicator of currency crises (Kaminsky et al. 1998). PPP may be used also as a benchmark for forecasting nominal exchange rates. If nominal exchange rates are very volatile and deviate significantly from their levels implied by the PPP, exchange rate uncertainty rises and the expected return on an international portfolio is negatively affected. The bulk of the empirical PPP literature has focused mainly on industrial countries (A. M. Taylor, M. P. Taylor 2004; Kutan, Zhou 2015). Recently, the research focus has shifted significantly to the emerging market economies and includes a wide range of methodologies. The examination of the behavior of RERs in Central and Eastern European (CEE) countries is interesting for at least two reasons. First, most of these countries are in the process of entering the eurozone, and in need of an estimate of the equilibrium exchange rate before they can connect their currency to the euro. If the hypothesis fails to uphold in these countries, then the PPP equilibrium rates may not provide a guideline for their exchange rate against the euro. Hence, knowledge of whether PPP holds for these countries using updated data set may help in assessing the readiness of these countries to join the European Monetary Union (EMU). Second, the confidence that international financial markets and asset managers place in these countries with regard to trade and investments depends on RER behavior. If PPP holds, there would be very little RER variation and hence almost no RER risk. This outcome would be important from the viewpoint of portfolio managers.

We focus on the validity of PPP between each of the transition economies and their major trading partners, namely the United States and the eurozone-member countries, given the importance of the dollar in the foreign exchange market and the increasing integration between the CEE countries and the eurozone. These countries experienced both nominal shocks and real shocks and were severely affected by the Russian and more recently the global financial crisis (GFC). These events imply a possible structural change in the estimation of persistence. In this context, the application of break model by Carrion-i-Silvestre et al.'s (2005) is of great interest.

The bulk of the PPP literature on CEE countries summarized in the next section is based on unit-root and cointegration tests and restricts its investigation to an $I(0) / I(1)$ RER process. Having established first RER stationarity, we depart from these studies by con- 
sidering an intermediate process, the local-persistent model proposed by Phillips et al. (2001), to calculate the point estimates of the half-life and their confidence intervals (CIs) and provide a novel solution to the PPP puzzle. A major attraction of this model is that it tends to produce narrower CIs for half-life deviations than those calculated from Augmented Dickey-Fuller (ADF) and local-to-unit root models. Our analysis also allows for structural changes in the estimation of persistence. We also compare for the first time the speed of convergence to PPP between the transition economies and the core European Union (EU) countries, noting that a near unit-root process best characterizes RERs in both the transition and developed economies. Our major conclusion is that RERs are stationary and the PPP puzzle does not apply for our data that include the CEE countries and some core EU countries. Both the dollar and euro bilateral exchange rates display similar persistence patterns.

The plan of the paper is as follows. The next section provides an overview of the PPP literature. Section 2 describes the methodology on the computation of half-life derived from the local-persistent model. Section 3 describes the data and presents the results. Section 4 concludes the paper.

\section{Literature review}

The literature on the major industrialized countries shows that point estimates of the half-life of RER shocks based on the standard ADF and local-to-unity models largely confirm the PPP puzzle stating that, while PPP holds for the majority of the countries, the speed of RER reversion to parity is, in many cases, rather slow (around 3-5 years) and at odds with sticky-price models. In addition, critics have pointed out that the reported wide CIs provide little information on the speed of convergence.

The empirical literature on PPP in transition economies has mushroomed recently. It includes, among others, Choudhry (1999), Payne et al. (2005), Sideris (2006), BahmaniOskooee et al. (2008), Barros et al. (2011) and Liu et al. (2012). The papers differ in terms of their sample period, country coverage, and methodology. Early studies used linear unit-root tests or cointegration tests and, in most cases, rejected PPP (Christev, Noorbakhsh 2000; Sideris 2006; Thacker 1995). This is not surprising for at least two reasons: First, during the catching-up phase of the transition, equilibrium exchange rates should exhibit an upward trend as the countries experience growth in productivity and real wages (De Broeck, Sløk 2006). Second, large capital flows due to capital account liberalization might appreciate RERs, thus invalidating long-run PPP. Recent studies used nonlinear and panel unit-root tests and in some cases allowed for structural change. Evidence for PPP is provided by Bahmani-Oskooee et al. (2008), Boršič et al. (2012), Chang et al. (2012), Cuestas (2009), Kasman et al. (2010), Koukouritakis (2009), Maican and Sweeney (2013), and Telatar and Hasanov (2009).

Some papers (Basher, Carrion-i-Silvestre 2013; Holmes et al. 2012; Maican, Sweeney 2013) highlight the importance of accounting for structural breaks in testing for PPP. The first two studies use Organization for Economic Co-operation and Development (OECD) data and the last one considers data on $10 \mathrm{CEE}$ countries. They all report faster 
mean reversion, i.e., smaller half-lives, in comparison with studies that ignore structural change. The above papers highlight the importance of exploring models that accommodate breaks as a means to obtain tighter CIs for half-lives and stronger evidence for long-run PPP. This point is taken up in our paper.

Most of the PPP studies on transition economies mentioned above focus on whether the RER series is an $I(0) / I(1)$ process and do not consider half-life deviations from PPP estimates as complementary to their unit-root tests. Thus, they are unable to address the PPP puzzle. Exceptions are Kasman et al. (2010), Chang et al. (2012), and Maican and Sweeney (2013). However, despite evidence in favor of PPP in many cases, the estimated half-lives are very large leading to the PPP puzzle. For example, Chang et al. (2012), despite the evidence for RER stationarity in the transition economies, they report half-life estimates between 7-64 months. In addition, this literature has not estimated CIs for half-lives and hence has ignored uncertainty surrounding their halflife estimates. The bulk of the literature suggests that standard measures of half-life might be problematic and spuriously unfavorable empirical results may be obtained on the parity condition when highly persistent processes are unaccounted for in the model (Murray, Papell 2002). Moreover, CIs of the half-life based on conventional methods assuming the RER is an $I(1) / I(0)$ process tend to be very wide (including the possibility of an infinite half-life), thereby providing virtually no information on the size of the half-lives. As illustrated in Rossi (2005), the standard sampling methods used in constructing CIs might be unreliable when the variables are highly persistent and the sample size is too small.

Given the poor performance of modeling the RER as an $I(0) / I(1)$ process, Kim and Lima (2010) suggest the estimation of a local-persistent model (Phillips et al. 2001), a process between a stationary and a unit-root process. This intermediate process allows the RER to show persistence over a range of time, but eventually the effects of shocks will dissipate in support of PPP. An important finding that emerges from this study is that the PPP puzzle is less pronounced than commonly thought. We depart from Kim and Lima (2010) by assuming that the persistence in RER is unstable over the sample period.

The present study combines two strands of the literature. First, it applies the localpersistent model to the transition economies of Europe. Second, it accounts for breaks in the data given the findings of recent studies that incorrect specification (including the actual number of breaks) may bias the analysis toward a finding of slow convergence. The allowance for breaks in the data for the transition economies is justified as the occurrence of major economic reforms and changing macroeconomic regimes may give a false impression of the speed of adjustment toward long-run equilibrium.

\section{Half-life measure}

We consider the local-persistent model proposed by Phillips et al. (2001) and extended by Lima and Xiao (2007) to model the in-between process, which lies between the conventional stationary and unit-root process, and capture the behavior of RERs in the transition countries included in our study. Following Kim and Lima (2010), the 
half-life property of local persistence is computed as $\ln (0.5 b(\hat{1})) /\left(-1 / n^{\hat{d}}\right)$, where the estimated local persistence parameter $\hat{d}=-\ln (1-\hat{\varphi}) / \ln (n)$. In the above expressions $b(\hat{1})=1-\sum_{j=1}^{k} \hat{\beta}_{j} \Delta R E R_{t-j}$ is the correction factor, $n$ is the number of observations and $\hat{\varphi}$ is a consistent estimator of the largest root measuring persistence and determined from the break models. The delta method is used to compute the two-sided 95 percent CIs (Lima, Xiao 2007) obtained by $\hat{h}_{0.50} \pm 1.96 \operatorname{se}(\hat{\varphi})\left[(-\ln 0.5 / \hat{\varphi})(\ln (\hat{\varphi}))^{-2}\right]$, where $\operatorname{se}(\hat{\varphi})=\sqrt{2} /\left(n^{\frac{1}{2}+\frac{\hat{d}}{2}}\right)$. If $d$ lies between 0 and 1 , the series is characterized as the standardized local persistence process. Two interesting special cases may be considered: when $d=1$, the series is identical to the local-to-unit root process proposed by Rossi (2005) and when $d=0$, the time-series process has short-memory dynamics. Sekioua (2008) argues that the unit-root null can seldom be rejected for highly persistent variables; hence, a misleading conclusion with regard to PPP will be drawn if the persistence of deviation from the parity is ignored in the measurement. The approach to test the local persistence parameter is described in Kim and Lima (2010).

\section{Data and empirical results}

\subsection{Data}

This paper investigates the PPP relationship over the period 1996:M1-2011:M10. It extends previous studies to include the effect of the GFC and the subsequent sovereign debt crises of the Euro countries. The transition countries include Bulgaria (BG), Croatia (CR), Czech Republic (CZ), Estonia (EE), Hungary (HU), Latvia (LV), Lithuania (LT), Poland (PL), Romania (RO), Slovakia (SK), and Slovenia (SL). Only three of these countries (EE, SK, and SL) had adopted the euro by the end of the sample period. Latvia joined the euro in January 2014. The sample period is dictated by the availability of the harmonized consumer price index (HCPI) ${ }^{1}$. The main source of the data is the Wiener Institut für Internationale Wirtschaftsvergleiche (WIIW) database. The national currency/euro exchange rate series for LV, LT, and EE were obtained from the Eurostat database, and the U.S.-based series come from the International Financial Statistics (IFS). The consumer price index data (CPI, 2005=100) and HCPI $(2005=100)$ were collected from IFS, the WIIW, and the Eurostat database. We also incorporate data on five EU countries, including the three largest - Belgium (BEL), France (FRA), Germany (DEU), Italy (ITA), and the Netherlands (NLD) for comparison. These series are not seasonally adjusted, and all the variables are expressed in logs.

\subsection{Unit-root tests}

In our preliminary analysis, we applied an array of unit-root tests. Unreported results from standard unit-root tests reject the PPP hypothesis in all but a few cases. Next, we consider two other unit-root tests allowing for breaks advocated by Carrion-i-Silvestre et al. (CDL 2005) and Narayan and Popp (2010). The former approach considers panel stationarity tests that account for both cross-sectional dependence and multiple struc-

\footnotetext{
${ }^{1}$ The sample also covers a period where capital controls had been abolished in the EU area.
} 
tural breaks, while the latter approach is a two-break unit-root test including breaks in the trend. An interesting feature of the Narayan and Popp (2010) approach is that the test statistic is invariant to breakpoint nuisance parameters under the null hypothesis. The single time-series two-break test which considers two different Innovational Outliers specifications for trending data (unreported) advocated by Narayan and Popp (2010) yields some support for $\mathrm{PPP}^{2}$. By contrast, the results from CDL reported in Table 1 that have the power advantages of panel unit-root tests fail to reject the stationary null, that is, long-run PPP holds. These results are quite robust as they apply for the two panels (the CEE panel and the CEE panel augmented with 5 EU countries), two different choices of breaks (two and five) and two reference currencies. The advantage of using the CDL panel test is that if the stationarity null is not rejected, then we can conclude that all of the series in the panel are stationary. We attribute the RER stationarity finding to the use of a model which allows for both structural breaks and cross-sectional dependence. Specifically, the test allows the following characteristics: (i) structural breaks can have heterogeneous effects on each individual series; (ii) these breaks can be located at different dates, and (iii) individuals can have a different number of structural breaks. This finding is in line with Cuestas (2009), Koukouritakis (2009), Maican and Sweeney (2013), and Telatar and Hasanov (2009) as they all find PPP support for most of the transition countries based on a different methodology.

The timing of the first break identified by the Bai and Perron's (2003) dynamic algorithm is concentrated around 1999-2001, which coincides with the 1998 Russian financial turmoil and the launching of the euro. The location of the second break during the period 2004-2006 may be associated with joining the EU (CR, CZ, HU, SK and EE). For the dollar rates, the cluster of breaks found for the 2007-2008 period picks up the depreciation of the euro during the GFC. The results are reasonable since the locations of the breaks coincide with economic and political factors in the region. It is also apparent from our findings that persistence in macroeconomic data could be the results of ignoring structural breaks in the data generating process. These break dates are taken into consideration in the analysis that follows.

\subsection{Half-life}

Having shown that each RER series is stationary, we now turn to the speed of adjustment to PPP, an issue that has received less attention in the literature. The fact that stationarity is not rejected cannot be interpreted as confirmation of mean reversion. As noted in Rossi (2005) and others, the outcome from the stationarity test may suggest mean reversion, but the speed of reversion to parity may be rather slow to support the hypothesis. The literature based mainly in the industrialized countries has recorded lengthy half-life estimates for RERs in the presence of a high degree of nominal and real exchange rate volatilities. We apply the local-persistent model instead of the ADF or the local-to-unit root model. The reason is that RERs are typically affected by mon-

\footnotetext{
${ }^{2}$ The test rejects the unit-root null in two (CZ and EE) out of 11 countries for the euro rates but in only one country (BG) for the dollar exchange rates.
} 
Table 1. Panel stationarity test with multiple breaks

\begin{tabular}{|c|c|c|c|c|c|c|c|c|c|c|}
\hline \multirow{3}{*}{$\begin{array}{c}\text { Test } \\
\text { statistics }\end{array}$} & \multicolumn{5}{|c|}{ Euro rates } & \multicolumn{5}{|c|}{ U.S. rates } \\
\hline & \multirow[t]{2}{*}{$\operatorname{SupF}(2 \mid 1)$} & \multirow[t]{2}{*}{$\operatorname{SupF}(3 \mid 2)$} & \multicolumn{3}{|c|}{ Date } & \multirow[t]{2}{*}{$\operatorname{SupF}(2 \mid 1)$} & \multirow[t]{2}{*}{$\operatorname{SupF}(3 \mid 2)$} & \multicolumn{3}{|c|}{ Date } \\
\hline & & & 1 & 2 & 3 & & & 1 & 2 & 3 \\
\hline $\mathrm{BG}$ & 3.54 & 0.86 & $00 / 7$ & & & $19.58^{\mathrm{a}}$ & 0.98 & $02 / 12$ & $07 / 6$ & \\
\hline $\mathrm{CR}$ & $18.78^{\mathrm{a}}$ & 1.93 & $01 / 3$ & $05 / 3$ & $07 / 12$ & $21.86^{\mathrm{a}}$ & $26.27^{\mathrm{a}}$ & $03 / 9$ & $07 / 3$ & \\
\hline $\mathrm{CZ}$ & $20.65^{\mathrm{a}}$ & $11.76^{\mathrm{b}}$ & $00 / 12$ & $05 / 7$ & $07 / 12$ & $13.31^{\mathrm{a}}$ & 0.06 & $03 / 3$ & $07 / 8$ & \\
\hline $\mathrm{HU}$ & $9.46^{\mathrm{b}}$ & 8.19 & $01 / 4$ & $06 / 10$ & & $15.52^{\mathrm{a}}$ & 0.05 & $02 / 11$ & $06 / 10$ & \\
\hline $\mathrm{PL}$ & 0.53 & 2.56 & $99 / 12$ & & & 2.48 & 2.57 & $04 / 9$ & & \\
\hline RO & 0.91 & 0.91 & $04 / 12$ & & & 2.52 & 1.51 & $04 / 10$ & & \\
\hline SK & $7.19^{\mathrm{c}}$ & $14.60^{\mathrm{a}}$ & $99 / 12$ & $03 / 12$ & $06 / 11$ & $9.66^{\mathrm{b}}$ & 1.44 & $03 / 2$ & $06 / 10$ & \\
\hline SL & $13.57^{\mathrm{a}}$ & $55.48^{\mathrm{a}}$ & $98 / 4$ & $01 / 9$ & $07 / 7$ & $16.98^{\mathrm{a}}$ & $22.47^{\mathrm{a}}$ & $99 / 12$ & $02 / 11$ & $07 / 3$ \\
\hline EE & 2.02 & 2.91 & $06 / 5$ & & & $17.61^{\mathrm{a}}$ & 0.18 & $03 / 3$ & $07 / 6$ & \\
\hline $\mathrm{LV}$ & 6.06 & 2.05 & $07 / 6$ & & & $17.42^{\mathrm{a}}$ & 0.01 & $03 / 10$ & $07 / 6$ & \\
\hline LT & $143.44^{\mathrm{a}}$ & 0.07 & $99 / 3$ & $07 / 12$ & & $25.63^{\mathrm{a}}$ & 0.04 & $02 / 11$ & $07 / 7$ & \\
\hline BEL & $14.60^{\mathrm{a}}$ & 1.26 & $02 / 6$ & $08 / 1$ & & 4.82 & 5.77 & $99 / 10$ & $02 / 12$ & $06 / 11$ \\
\hline FRA & $81.16^{\mathrm{a}}$ & 4.93 & $00 / 6$ & $06 / 9$ & & 2.88 & 3.19 & $99 / 10$ & $02 / 12$ & $06 / 11$ \\
\hline$\overline{\mathrm{DEU}}$ & $14.32^{\mathrm{a}}$ & $21.25^{\mathrm{a}}$ & $01 / 8$ & $06 / 2$ & & 3.03 & 4.15 & $99 / 10$ & $02 / 12$ & $06 / 11$ \\
\hline ITA & $78.44^{\mathrm{a}}$ & $20.98^{\mathrm{a}}$ & $98 / 9$ & $03 / 3$ & $08 / 9$ & 5.16 & 5.06 & $99 / 11$ & $02 / 12$ & $06 / 11$ \\
\hline \multirow[t]{2}{*}{ NLD } & $29.34^{\mathrm{a}}$ & 8.14 & $00 / 12$ & $07 / 5$ & & 3.53 & 5.38 & $99 / 10$ & $02 / 12$ & $07 / 2$ \\
\hline & \multicolumn{2}{|c|}{$m=2$} & \multicolumn{2}{|c|}{$m=5$} & & \multicolumn{2}{|c|}{$m=2$} & \multicolumn{3}{|c|}{$m=5$} \\
\hline \multicolumn{11}{|c|}{ Panel A: 11 CEE countries } \\
\hline $\begin{array}{l}Z(\lambda) \\
\text { homog- } \\
\text { enous }\end{array}$ & -2.17 & (0.99) & \multicolumn{2}{|c|}{-2.52} & (0.99) & -3.59 & (0.99) & \multicolumn{2}{|c|}{-2.76} & $(0.99)$ \\
\hline \multirow[t]{2}{*}{$\begin{array}{l}Z(\lambda) \\
\text { heterog- } \\
\text { enous }\end{array}$} & 1.24 & $(0.11)$ & \multicolumn{2}{|c|}{-0.72} & $(0.77)$ & -1.59 & $(0.94)$ & \multicolumn{2}{|c|}{-2.06} & $(0.98)$ \\
\hline & \multicolumn{7}{|c|}{ Panel B: 11 CEEC plus EU-5 } & \multirow{2}{*}{\multicolumn{2}{|c|}{-3.28}} & \\
\hline $\begin{array}{l}Z(\lambda) \\
\text { homog- } \\
\text { enous }\end{array}$ & -2.63 & (0.99) & \multicolumn{2}{|c|}{-3.21} & (0.99) & -4.24 & (0.99) & & & $(0.99)$ \\
\hline $\begin{array}{l}Z(\lambda) \\
\text { heterog- } \\
\text { enous }\end{array}$ & 1.28 & $(0.11)$ & 1. & 03 & $(0.15)$ & -1.40 & $(0.92)$ & -1 & .24 & $(0.89)$ \\
\hline
\end{tabular}

Notes: $\left({ }^{\mathrm{a}}\right),\left({ }^{\mathrm{b}}\right)$ and $\left({ }^{c}\right)$ denote significant at 1,5 and 10 percent significance level, respectively. We considered the pure structural change model up to five breaks. $Z(\lambda)$ homogenous and $Z(\lambda)$ heterogenous denote the CDL (2005) KPSS test assuming homogeneity and heterogeneity in the estimation of the long-run variance, respectively. The finite sample critical values are computed by means of Monte Carlo simulations using 10,000 replications. Figures in parenthesis are $p$-values and $m$ indicates the number of breaks allowed in the model using the sequential procedure. The trimming is taken on the interval $[0.1 n, 0.9 n]$, where $n$ is the sample size. 
etary and financial shocks. Table 2 (Panel A) reports the degree of local persistence of the stochastic process $(d)$, the corresponding half-life estimates, and the associated 95 percent CIs for $11 \mathrm{CEE}$ countries. Similar information on the monthly RERs of five EU countries vis-à-vis the euro and the U.S. dollar are reported in Panel B.

The results reported in Table 2 (columns 2-9) are quite interesting. First, the estimated local persistence parameter $(d)$ varies from $0.19(\mathrm{CZ})$ to $0.51(\mathrm{LV})$ for euro exchange rates, and from 0.19 (BG) to 0.51 (LV) for the U.S. dollar exchange rates. Second, for the euro-based exchange rates, we obtain point estimates of half-lives that range from 1.87 months (CZ) to 10.19 months (LV). Similarly, for US dollar exchange rates our half-life estimates range from 1.91 months (BG) to 9.83 months (LV). Third, the estimated CIs show that the half-life of PPP deviation varies widely across our sample countries, but none of the upper bounds of these intervals exceeds 18 months, irrespective of the reference currency. Fourth, similar results regarding the estimated half-lives and their CIs apply for the five EU countries. In the majority of countries, the upper bound of the CIs is less than one year. The only exceptions are Belgium and the Netherlands (for the dollar exchange rate), where the upper bound is approximately 15 months. These results contrast sharply with previous literature using a different methodology. Specifically, we find that the RER reverts to its equilibrium at a rate much faster than in previous studies, as the shocks have been removed with the inclusion of dummy variables in the model, according to the conclusions of the break tests. The euro dollar regime that started in January 1999 has not weakened PPP as a long-run relation in the EU countries. Our findings on the relatively small half-lives in the CEE countries echo the view expressed in Maican and Sweeney (2013). These countries typically had 10 years or less to make the huge adjustments that are required for accession to the EU. It would be interesting to compare the estimated half-lives and the respective CIs for the CEE and EU countries with those obtained from the traditional ADF model. With very few exceptions, the half-life estimates are much higher and the CIs much wider than those obtained from the Narayan and Popp model (columns 10-17).

Finally, to address the issue of the impact of the recent GFC on RERs behavior, we carry out the above computations for a reduced sample ending in 2006:M12. Unreported results for the sub-period 1996-2006 for the U.S. dollar and euro rates show substantially lower persistence, a finding rather expected given the GFC started in 2007. The estimated median half-lives are 4.20 and 4.01 months for the euro and U.S. RERs, respectively. The median half-life is shorter than for the full sample that cut across the break dates ${ }^{3}$. All the countries are found to exhibit mean reversion and possess compact half-life CIs. For most countries, the half-life point estimates are less than six months with upper bounds not exceeding 12 months. The median upper bounds are 6.34 and 6.70 months for the U.S. dollar and euro RERs, respectively. The two sets of bilateral rates from the bias corrected half-lives display similar persistence patterns. The differences in the speed of mean reversion between the long and short sample periods suggest changes in the speed of mean reversion over time. We formally test $\left(\hat{Q}_{n}\right)$ the null

\footnotetext{
${ }^{3}$ The median half-life for the full sample is 6.76 for the dollar rates while it is 6.09 for the euro RERs.
} 


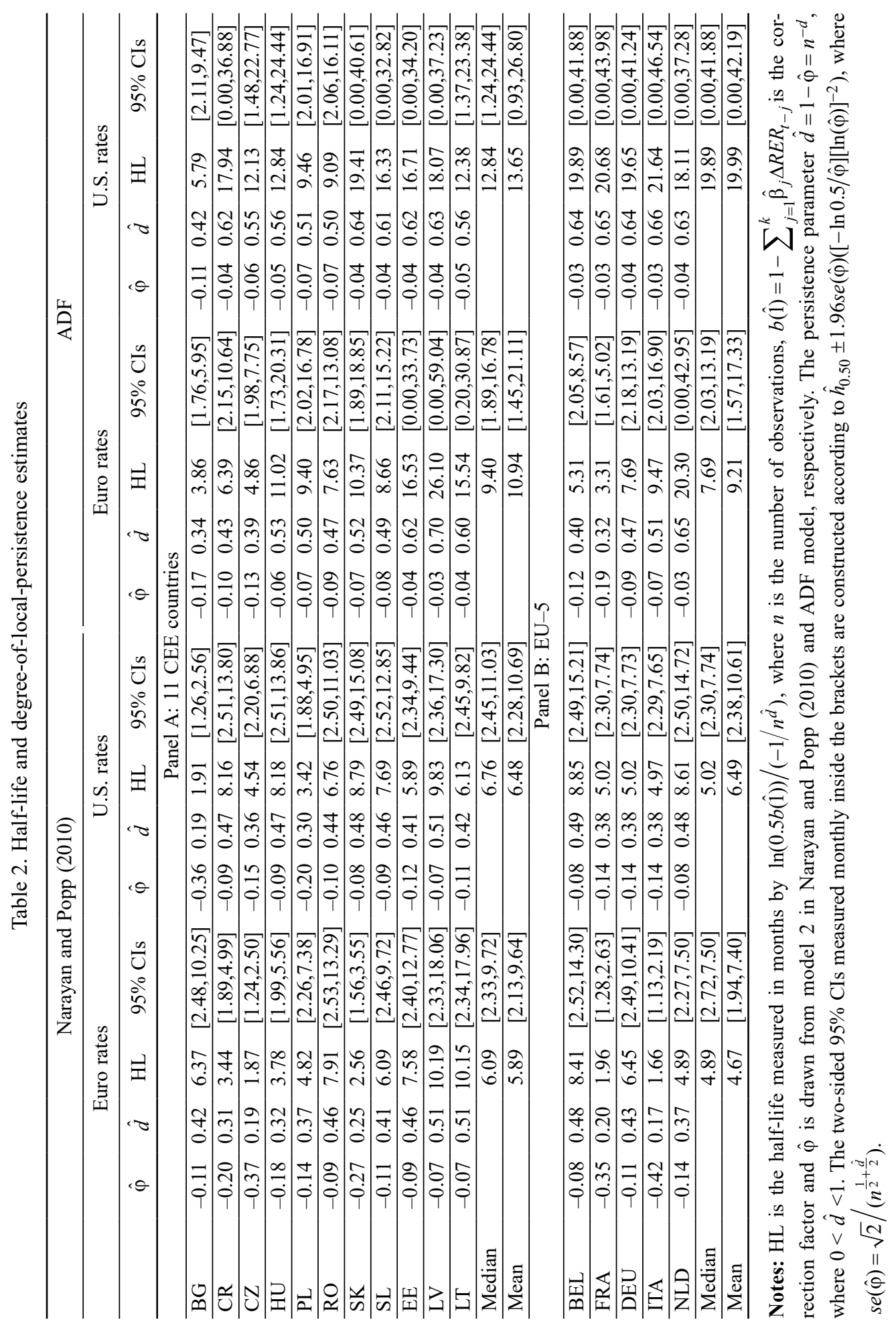


$H_{0}: d=0$ against $H_{1}: 0<d<1$ and the results (Table 3) show that all of the $\hat{d}$ are significantly different from zero. As in Kim and Lima (2010) and Baharumshah et al. (2015), we find strong support of the locally persistent process in the RER.

Table 4 summarizes the proportion of upper-bound estimates of half-lives for three time intervals (less than 6 months, from 6-12 months, and more than 12 months) for $11 \mathrm{CEE}$ countries, EU-5, and EU-16 (11 CEE plus EU-5) countries. Notice that the majority of the upper bounds of the CIs fall in the first and second categories and only a small proportion fits into the third category of more than 12 months. Specifically, around 64 percent (55 percent) of our half-life estimates for CEE countries are less than 12 months for euro- (U.S. dollar) rates. As shown in Table 4, the EU countries also have short-lived estimates-80 percent and 60 percent are less than 12 months for the euro and U.S. dollar rates, respectively. The last two lines of Table 4 report the mean and median of the upper bounds of the half-lives in each country group. The median upper bound for the CEE countries is only about two months larger than the corresponding figure for the EU countries. These findings indicate that the proportions of the upper bounds of the half-lives, as well as, the median of the upper bounds in the two groups are not

Table 3. Test statistics for $Q_{n}$ and $\hat{Q}_{n}$

\begin{tabular}{|c|c|c|c|c|}
\hline & \multicolumn{2}{|c|}{$Q_{n}$} & \multicolumn{2}{|c|}{$\hat{Q}_{n}$} \\
\hline & Euro rates & U.S. rates & Euro rates & U.S. rates \\
\hline \multicolumn{5}{|c|}{ Panel A: 11 CEE countries } \\
\hline BG & 1.63 & $3.04^{\mathrm{a}}$ & $4.98^{\mathrm{a}}$ & $5.99^{\mathrm{a}}$ \\
\hline $\mathrm{CR}$ & 0.15 & 0.52 & $5.86^{\mathrm{a}}$ & $5.46^{\mathrm{a}}$ \\
\hline $\mathrm{CZ}$ & 0.28 & 0.52 & $5.70^{\mathrm{a}}$ & $6.06^{\mathrm{a}}$ \\
\hline $\mathrm{HU}$ & 0.16 & 0.28 & $5.93^{\mathrm{a}}$ & $6.15^{\mathrm{a}}$ \\
\hline PL & 0.35 & 0.87 & $4.40^{\mathrm{a}}$ & $5.99^{\mathrm{a}}$ \\
\hline RO & 0.77 & 1.39 & $5.23^{\mathrm{a}}$ & $6.19^{\mathrm{a}}$ \\
\hline SK & $3.80^{\mathrm{a}}$ & $5.85^{\mathrm{a}}$ & $6.15^{\mathrm{a}}$ & $6.28^{\mathrm{a}}$ \\
\hline $\mathrm{SL}$ & $5.00^{\mathrm{a}}$ & $3.51^{\mathrm{a}}$ & $5.01^{\mathrm{a}}$ & $5.29^{\mathrm{a}}$ \\
\hline $\mathrm{EE}$ & 0.20 & 0.46 & $5.15^{\mathrm{a}}$ & $5.79^{\mathrm{a}}$ \\
\hline LV & 1.29 & 1.85 & $4.65^{\mathrm{a}}$ & $5.92^{\mathrm{a}}$ \\
\hline LT & 0.65 & 1.23 & $5.14^{\mathrm{a}}$ & $6.11^{\mathrm{a}}$ \\
\hline \multicolumn{5}{|c|}{ Panel B: EU-5 } \\
\hline BEL & 0.01 & 0.19 & $2.20^{\mathrm{b}}$ & $4.65^{\mathrm{a}}$ \\
\hline FRA & 0.03 & 0.34 & $4.98^{\mathrm{a}}$ & $4.25^{\mathrm{a}}$ \\
\hline DEU & 0.21 & 1.07 & $5.86^{\mathrm{a}}$ & $3.97^{\mathrm{a}}$ \\
\hline ITA & 0.01 & 0.10 & $5.07^{\mathrm{a}}$ & $5.08^{\mathrm{a}}$ \\
\hline NLD & 0.12 & 1.06 & $4.67^{\mathrm{a}}$ & $4.89^{\mathrm{a}}$ \\
\hline
\end{tabular}

Notes: The test statistics $Q_{n}$ based on RER and $\hat{Q}_{n}$ based on the demeaned value of RER for each country are computed under the null hypothesis of covariance stationarity. $\left({ }^{\mathrm{a}}\right)$ and $\left({ }^{\mathrm{b}}\right)$ denote statistical significance at 0.01 and 0.05 , respectively. The critical values of $Q_{n}$ and $\hat{Q}_{n}$ are tabulated in Table A.1. 
very different after all. Hence, the claim that PPP usually holds in countries with high inflation rather than low inflation does not have strong empirical support. Many of the transition economies adopted trade policies that mimic those in member countries of the EU. Kutan and Yigit (2004) find increasing similarities in real and monetary developments between the eurozone and its CEE partners. As their growth and inflation rates converge to those of the developed economies, we can expect the persistence of the RERs to match closely with that of the advanced EU countries.

Table 4. Proportion of the upper bound of the half-life

\begin{tabular}{lccc}
\hline & Panel A & Panel B & Panel C \\
\hline & 11 CEE countries & EU-5 & 11 CEE countries plus EU-5 \\
\hline HL $<$ 6 months (\%) & 36.36 & 40.00 & 37.50 \\
& $(18.19)$ & $(0.00)$ & $(12.50)$ \\
\hline \multirow{2}{*}{ months $\leq$ HL $\leq 12$ months (\%) } & 27.28 & 40.00 & 31.25 \\
& $(36.36)$ & $(60.00)$ & $(43.75)$ \\
\hline \multirow{2}{*}{ months $<$ HL (\%) } & 36.36 & 20.00 & 31.25 \\
Mean (months) & $(45.45)$ & $(40.00)$ & $(43.75)$ \\
\hline Median (months) & $9.64(10.69)$ & $7.40(10.61)$ & $8.94(10.66)$ \\
\hline
\end{tabular}

Notes: The table shows the proportion of upper-bound estimates of half-lives (HL) below 6 months, 6-12 months, and above 12 months. The values in parentheses refer to the proportion of the half-lives for the U.S. dollar-based rate. The mean and the median refer to the upper bound of the CIs of the half-life computed from model 2 of the Narayan and Popp (2010) test reported in Table 2.

Finally, we extend our empirical findings by analyzing the dynamics of PPP deviation persistence for 5 years rolling-window estimates against the end year of sample period for the U.S. and euro series. First, we estimate the persistence parameter using a 5 years sample (1996:M1-2000:M12) using the Kim and Lima (2010) procedure. Twelve observations (2001:M1-2001:M12) are then added to re-estimate the persistence parameter. This one-year increment in the procedure is repeated until the end of the sample period. According to Okimoto and Shimotsu (2010: 404), the dynamics of PPP deviation persistence "...can help highlight the periods over which there would likely have been a pronounced decline in the persistence of PPP deviations". Figure 1 displays the 5 years rolling-window estimates of the persistence parameter for all real bilateral rates. We notice the persistence of PPP deviations decreases sharply after 2008. This additional information provides further evidence supporting the notion that the speed of PPP adjustment tends to be faster in periods of high economic uncertainty.

\subsection{Comparison with related literature}

Our results indicate that the estimated half-lives in all countries are less than 12 months and the upper bounds of the CIs are below 18 months. These results are robust to the reference currency and the end-year of our sample. They indicate an absence of the PPP puzzle in the CEE and EU-5 countries, implying that shocks to RERs are best viewed as transitory. 


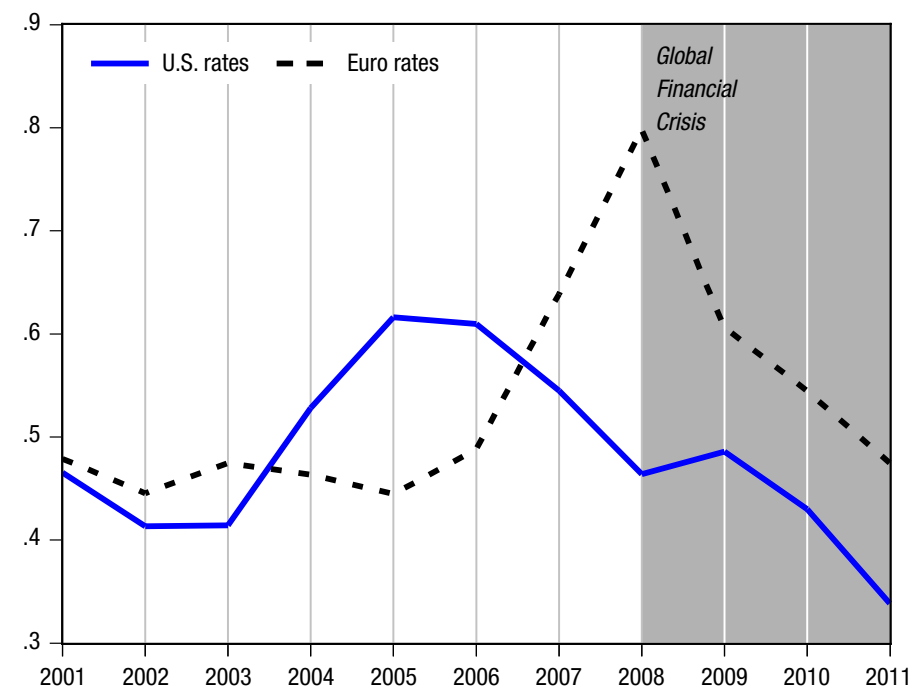

Fig. 1. Dynamics of RER deviation persistence based on 5 years rolling-window against the end year of sample period

Therefore, we conclude that the behavior of RERs in the transition countries appears to be consistent with the sticky-price models of exchange rate determination. The overwhelming majority of PPP papers on CEE countries does not estimate half-lives and hence cannot fully test for PPP in the sense of addressing the PPP puzzle. The most relevant paper in the literature from the aspect of the applied methodology is Kim and Lima (2010). They use data on major industrialized countries and apply the localpersistent model to estimate half-lives overlooking the possibility of breaks and change in persistence of RERs. They provide point estimates in the order of 3.1-3.2 years for Germany and France, which lie within Rogoff's range and hence support the PPP puzzle. In addition, the CIs upper bounds reported by Kim and Lima (2010) are almost 5 years, i.e., much wider than those obtained in our case.

A number of studies have argued that nonlinear models should be applied to solve the PPP puzzle. Zhou et al. (2008) find that convergence toward PPP between EU (and especially between the euro area) countries tend to follow a nonlinear path. Although some papers find that PPP holds for the countries under consideration, there is substantial uncertainty about the half-life of shocks to the RER. He and Chang (2013) using nonlinear models and smooth structural change report half-lives for real effective exchange rate of about 20 months, with four countries (namely Austria, Bulgaria, Slovakia and Romania) in the infinite range. Our results, however, reveal that there is no PPP puzzle based on the linear model that accounts for breaks. Linear half-lives from the local-persistent model are short and their corresponding CIs are much narrower than previously reported. 


\section{Conclusions}

We contribute to the PPP puzzle debate by offering an additional perspective on the exploration of mean reversion in RERs for the CEE countries. Based on stationarity tests and half-life estimates from the local-persistent model, we obtain a number of interesting results. First, we find that the dynamics of RERs are described by a transient process that reverts to its fixed mean after major economic shocks, a characteristic that accords with the PPP hypothesis, with persistence estimates lower than in the standard stationarity process. Second, we find that, accounting for structural breaks, the estimated half-life is less than 12 months with an estimated CIs upper bound below 18 months, thus supporting the notion that the PPP puzzle disappears when both a more general persistence process and structural breaks are accounted for in the data. The speed of adjustment to PPP is unstable and faster during periods of high economic uncertainty as the GFC. We take these findings as further evidence to suggest that the puzzle reported in previous studies may have been overstated.

A third and rather striking finding is that accounting for breaks, the array of point halflife estimates, as well as, the upper bounds of the CIs are well within the vicinity of the larger EU countries (below 18 months). This means that the degree of economic integration in the CEE countries is no different from that of their neighboring core members. Our findings endorse the view that the CEE countries have successfully aligned their trade policies to those of the EU, in preparation for EU membership.

The policy implications of this study are noteworthy. First, both the euro and U.S. dollar RERs have limited harmful effects on the long-run competitiveness and trade flows of the CEE countries. Second, PPP provides a useful tool for the transition countries to determine whether their currency is over- or under-valued. The cost of adoption of euro by these countries would not be high since the speed of adjustment is rapid and not much different from the larger EU members. The above analysis could be extended to incorporate regime shifts. It is well known that the real sector in these transition economies has gone through drastic changes since the implementation of economic reform programs. The empirical application of nonlinear methods may unveil some of the salient features of the RERs in these countries. This exercise is left for future research.

\section{Acknowledgments}

The authors would like to thank the Editor and anonymous referees of this journal for very constructive comments on earlier versions of the paper. Financial support from Universiti Putra Malaysia [Grant No. 06-02-12-2255RU] is gratefully acknowledged. 


\section{References}

Baharumshah, A. Z.; Soon, S.-V.; Wohar, M. E. 2015. Parity reversion in the Asian real exchange rates: new evidence from the local-persistent model, Applied Economics 47(59): 6395-6408. http://dx.doi.org/10.1080/00036846.2015.1071474

Bahmani-Oskooee, M.; Kutan, A. M.; Zhou, S. 2008. Do real exchange rates follow a nonlinear mean reverting process in developing countries?, Southern Economic Journal 74(4): 1049-1062. http://dx.doi.org/10.2307/20112014

Bai, J.; Perron, P. 2003. Computation and analysis of multiple structural change models, Journal of Applied Econometrics 18(1): 1-22. http://dx.doi.org/10.1002/jae.659

Barros, C. P.; Gil-Alana, L.; Matousek, R. 2011. Fractional integration of nominal exchange rates: evidence from CEECs in the light of EMU enlargement, Review of International Economics 19(1): 77-92. http://dx.doi.org/10.1111/j.1467-9396.2010.00933.x

Basher, S. A.; Carrion-i-Silvestre, J. L. 2013. Deconstructing shocks and persistence in OECD real exchange rates, The B.E. Journal of Macroeconomics 13(1): 1935-1969.

http://dx.doi.org/10.1515/bejm-2012-0060

Boršič, D.; Baharumshah, A. Z.; Bekő, J. 2012. Are we getting closer to purchasing power parity in Central and Eastern European economies?, Applied Economics Letters 19(1): 87-91.

http://dx.doi.org/10.1080/13504851.2011.568383

Carrion-i-Silvestre, J. L.; Del Barrio-Castro, T.; López-Bazo, E. 2005. Breaking the panels: an application to the GDP per capita, Econometrics Journal 8(2): 159-175.

http://dx.doi.org/10.1111/j.1368-423X.2005.00158.x

Chang, T.; Lee, C.-H.; Chou, P.-I.; Wang, S.-C. 2012. Purchasing power parity for transition countries: further evidence from panel SURADF test with a Fourier function, Eastern European Economics 50(4): 42-59. http://dx.doi.org/10.2753/EEE0012-8775500403

Choudhry, T. 1999. Purchasing power parity in high-inflation eastern European countries: evidence from fractional and Harris-Inder cointegration tests, Journal of Macroeconomics 21(2): 293-308. http://dx.doi.org/10.1016/S0164-0704(99)00104-4

Christev, A.; Noorbakhsh, A. 2000. Long-run purchasing power parity, prices and exchange rates in transition: the case of six Central and East European countries, Global Finance Journal 11(1-2): 87-108. http://dx.doi.org/10.1016/S1044-0283(00)00016-8

Cuestas, J. C. 2009. Purchasing power parity in Central and Eastern European countries: an analysis of unit roots and nonlinearities, Applied Economics Letters 16(1): 87-94.

http://dx.doi.org/10.1080/13504850802112252

De Broeck, M.; Sløk, T. 2006. Interpreting real exchange rate movements in transition countries, Journal of International Economics 68(2): 368-383.

http://dx.doi.org/10.1016/j.jinteco.2005.05.012

He, H.; Chang, T. 2013. Purchasing power parity in transition countries: sequential panel selection method, Economic Modelling 35(September): 604-609.

http://dx.doi.org/10.1016/j.econmod.2013.08.021

Holmes, M. J.; Otero, J.; Panagiotidis, T. 2012. PPP in OECD countries: an analysis of real exchange rate stationarity, cross-sectional dependency and structural breaks, Open Economies Review 23(5): 767-783. http://dx.doi.org/10.1007/s11079-011-9234-0

Kaminsky, G.; Lizondo, S.; Reinhart, C. M. 1998. Leading indicators of currency crisis, International Monetary Fund Staff Papers 45(1): 1-48. http://dx.doi.org/10.2307/3867328

Kasman, S.; Kasman, A.; Ayhan, D. 2010. Testing the purchasing power parity hypothesis for the new member and candidate countries of the European Union: evidence from Lagrange Multiplier unit root tests with structural breaks, Emerging Markets Finance and Trade 46(2): 53-65.

http://dx.doi.org/10.2753/REE1540-496X460204 
Kim, S.; Lima, L. R. 2010. Local persistence and the PPP hypothesis, Journal of International Money and Finance 29(3): 555-569. http://dx.doi.org/10.1016/j.jimonfin.2009.07.006

Koukouritakis, M. 2009. Testing the purchasing power parity: evidence from the new EU countries, Applied Economics Letters 16(1): 39-44. http://dx.doi.org/10.1080/13504850701735807

Kutan, A. M.; Yigit, T. M. 2004. Nominal and real stochastic convergence of transition economies, Journal of Comparative Economics 32(1): 23-36. http://dx.doi.org/10.1016/j.jce.2003.09.008

Kutan, A. M.; Zhou, S. 2015. PPP may hold better than you think: smooth breaks and non-linear mean reversion in real effective exchange rates, Economic Systems 39(2): 358-366.

http://dx.doi.org/10.1016/j.ecosys.2014.12.001

Lima, L. R.; Xiao, Z. 2007. Do shocks last forever? Local persistency in economic time series, Journal of Macroeconomics 29(1): 103-122. http://dx.doi.org/10.1016/j.jmacro.2005.04.005

Liu, S.; Zhang, D.; Chang, T. 2012. Purchasing power parity-nonlinear threshold unit root test for transition countries, Applied Economics Letters 19(18): 1781-1785.

http://dx.doi.org/10.1080/13504851.2012.654905

Maican, F. G.; Sweeney, R. J. 2013. Real exchange rate adjustment in European transition countries, Journal of Banking and Finance 37(3): 907-926.

http://dx.doi.org/10.1016/j.jbankfin.2012.10.007

Murray, C. J.; Papell, D. H. 2002. The purchasing power parity persistence paradigm, Journal of International Economics 56(1): 1-19. http://dx.doi.org/10.1016/S0022-1996(01)00107-6

Narayan, P. K.; Popp, S. 2010. A new unit root test with two structural breaks in level and slope at unknown time, Journal of Applied Statistics 37(9): 1425-1438.

http://dx.doi.org/10.1080/02664760903039883

Okimoto, T.; Shimotsu, K. 2010. Decline in the persistence of real exchange rates, but not sufficient for purchasing power parity, Journal of the Japanese and International Economies 24(3): 395-411. http://dx.doi.org/10.1016/j.jjie.2010.06.001

Payne, J.; Lee, J.; Hofler, R. 2005. Purchasing power parity: evidence from a transition economy, Journal of Policy Modelling 27(6): 665-672. http://dx.doi.org/10.1016/j.jpolmod.2005.03.001

Phillips, P. C. B.; Moon, H. R.; Xiao, Z. 2001. How to estimate autoregressive roots near unity, Econometric Theory 17(1): 29-69. http://dx.doi.org/10.1017/S0266466601171021

Rogoff, K. 1996. The purchasing power parity puzzle, Journal of Economic Literature 34(2): 647-668.

Rossi, B. 2005. Confidence intervals for half-life deviations from purchasing power parity, Journal of Business and Economic Statistics 23(4): 432-442.

http://dx.doi.org/10.1198/073500105000000027

Sekioua, S. H. 2008. Real interest parity (RIP) over the 20th century: new evidence based on confidence intervals for the largest root and the half-life, Journal of International Money and Finance 27(1): 76-101. http://dx.doi.org/10.1016/j.jimonfin.2007.09.002

Sideris, D. 2006. Purchasing power parity in economies in transition: evidence from Central and East European countries, Applied Financial Economics 16(1-2): 135-143.

http://dx.doi.org/10.1080/09603100500390141

Taylor, A. M.; Taylor, M. P. 2004. The purchasing power parity debate, Journal of Economic Perspectives 18(4): 135-158. http://dx.doi.org/10.1257/0895330042632744

Telatar, E.; Hasanov, M. 2009. Purchasing power parity in Central and East European countries, Eastern European Economics 47(5): 25-41. http://dx.doi.org/ 10.2753/EEE0012-8775470502

Thacker, N. 1995. Does PPP hold in the transition economies? The case of Poland and Hungary, Applied Economics 27(6): 477-481. http://dx.doi.org/10.1080/00036849500000134

Zhou, S.; Bahmani-Oskooee, M.; Kutan, A. M. 2008. Purchasing power parity before and after the adoption of the Euro, Review of World Economics 144(1): 134-150.

http://dx.doi.org/10.1007/s10290-008-0140-5 


\section{APPENDIX}

Table A.1. Upper tail critical values for $Q_{n}$ and $\hat{Q}_{n}$

\begin{tabular}{|c|c|c|c|}
\hline \multirow{2}{*}{ Sample size $n$} & \multirow{2}{*}{ Level of significance } & \multicolumn{2}{|c|}{ Critical value } \\
\hline & & $Q_{n}$ & $\hat{Q}_{n}$ \\
\hline \multirow{3}{*}{70} & 0.10 & 1.90 & 1.92 \\
\hline & 0.05 & 2.18 & 2.19 \\
\hline & 0.01 & 2.76 & 2.76 \\
\hline \multirow{3}{*}{100} & 0.10 & 1.90 & 1.91 \\
\hline & 0.05 & 2.16 & 2.16 \\
\hline & 0.01 & 2.68 & 2.68 \\
\hline \multirow{3}{*}{200} & 0.10 & 1.92 & 1.92 \\
\hline & 0.05 & 2.19 & 2.20 \\
\hline & 0.01 & 2.81 & 2.81 \\
\hline \multirow{3}{*}{500} & 0.10 & 1.91 & 1.91 \\
\hline & 0.05 & 2.21 & 2.21 \\
\hline & 0.01 & 2.73 & 2.74 \\
\hline \multirow{3}{*}{1,000} & 0.10 & 1.96 & 1.96 \\
\hline & 0.05 & 2.24 & 2.24 \\
\hline & 0.01 & 2.77 & 2.77 \\
\hline
\end{tabular}

Notes: The critical values of test statistics $Q_{n}$ and $\hat{Q}_{n}$ are computed under the null hypothesis of covariance stationarity. The results are taken at the upper tail of the level of significance: $0.10,0.05$ and 0.01 for the sample size $(n)=70,100,200,500$ and 1,000, and are based on 5,000 replications.

Ahmad Zubaidi BAHARUMSHAH is a Professor at the Faculty of Economics and Management, Universiti Putra Malaysia. His area of interest is in International Finance and Macroeconomics and to date has published more than 80 research articles.

Siew-Voon SOON currently is a postdoctoral researcher at the Faculty of Economics and Management, Universiti Putra Malaysia. Her research interests are mainly in Macroeconomics, International Finance and Applied Econometrics.

Stilianos FOUNTAS is a Professor of Economics at the University of Macedonia in Greece. He has worked previously at the National University of Ireland, Galway. He has held visiting appointments at the University of York in the UK and the University of California at San Diego. He has published extensively in the areas of Applied Macroeconomics and International Finance. He has more than 45 publications in international refereed journals including the Journal of International Money and Finance, Oxford Bulletin of Economics and Statistics and Economics Letters.

Nurul Sima MAHAMAD SHARIF is a lecturer at Faculty of Science and Technology, Universiti Sains Islam Malaysia, Nilai, Negeri Sembilan, Malaysia. Her main areas of research interest are robust statistics, panel data analysis and statistical computing. 